\title{
En memoria de Christian Confavreux In memorian Christian Confavreux
}

\section{Sr. Editor:}

Hace ya aproximadamente 6 meses ha partido uno de los grandes referentes de la neurología a nivel mundial; el profesor Christian Confavreux, quien es reconocido ampliamente por su valioso aporte al conocimiento de la historia natural de la Esclerosis Múltiple, gracias a los numerosos estudios y publicaciones que lideró. El 20 de septiembre de 2013, a los 64 años de edad y luego de una larga lucha contra la enfermedad que padecía los últimos años, falleció en Lyon-Francia, la ciudad donde se desarrolló profesionalmente y formó su familia.

¿Por qué escribir estas palabras? primeramente por la importancia del aporte del profesor Confavreux a la neurología y en particular a la Esclerosis Múltiple, y por la sentida pérdida que significó su muerte; después, porque tuve el honor de conocerlo y ser uno de sus múltiples discípulos; ya que en su entrega de experiencia y conocimiento no había mezquindad, contribuyendo a la formación de numerosos médicos, neurólogos y no neurólogos, en el servicio de neurología que dirigió desde 1988 hasta su muerte. Numerosos fueron los cargos ligados a su intensa actividad en la neurología: Profesor de neurología desde 1988 (sin duda de los que más le enorgullecía), fue presidente de ECTRIMS, presidente de la Sociedad Francesa de Neurología, presidente de la Fundación Eugène Devic EDMUS contra la Esclerosis Múltiple, líder del Observatoire Français de la Sclérose en Plaques (OFSEP), director de Neurobiotec Biological Resource Centre y miembro del Centre de Recherche en Neurosciences de Lyon.

¿Por qué escribirlas aquí? Es indudable que pese a la distancia geográfica mantenía un fuerte nexo con Chile: como miembro activo de la sociedad Franco-Chilena de neurología lo que le permitió visitarnos en dos oportunidades, y además parti-

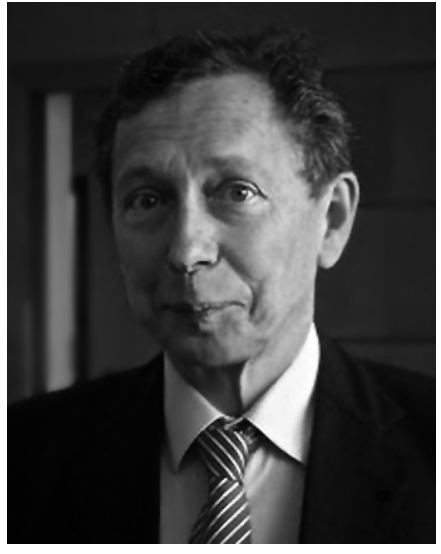

cipó como docente en el Diplomado de Esclerosis Múltiple 2012 y 2013 (on-line por Medichi) dirigido por el Prof. Dr. Jorge Nogales-Gaete, con quien compartía una importante amistad académica.

Con entrega y generosidad me acogió en su servicio durante un año gracias a una beca de la Sociedad Francesa de Neurología; y estuvo hasta sus últimos momentos siempre disponible para consultas y opiniones sobre el tema que le apasionaba y dedicó su carrera. En ese sentido su partida fue en un momento lleno de proyectos y actividad profesional, basta hacer una búsqueda en Pubmed y durante el 2013 aparecen publicados 9 artículos donde participó como autor (de los más de 200 que arroja el indexador), varios de ellos publicados después de su muerte.

¿Por qué escribir ahora? pese al paso de los meses sin duda se le extraña, no sólo desde la comunidad neurológica y sus colaboradores más cercanos, sino también su familia, la que formó en Lyon con su esposa y colega Elizabeth, coincidentemente bisnieta de otro gran neurólogo Lyonés, el profesor Eugène Devic, famoso por la enfermedad que lleva su nombre, y en la que el profesor Confavreux también aportó conocimiento.

Finalmente, es válido mencionar que la relación entre la neurología chilena y francesa, se mantiene viva y productiva actualmente gracias en buena parte, al dedicado trabajo de la Dra. Patricia Muñoz-Lacoste y la sociedad franco-chilena de neurología que dirige, y que como próximo 
proyecto tiene la realización de un estudio colaborativo sobre epidemiología de la Esclerosis Múltiple en Chile, al cual estamos todos los interesados en el tema invitados en participar, y que en cuya contraparte francesa colaborarán dos de los "legatarios neurológicos" del profesor Confavreux: la profesora Sandra Vukusic -quien se ha hecho cargo de la dirección del servicio de neurología dejado por el Dr. Confavreux-, y el profesor Thibault Moreau de Dijon.

\section{Dr. Sergio Cepeda Z.}

Neurólogo, Complejo Asistencial

Barros Luco Trudeau 